\title{
The evolution of systolic blood pressure as a strong predictor of cardiovascular risk and the effectiveness of fixed-dose $A R B / C C B$ combinations in lowering levels of this preferential target
}

Jean-Jacques Mourad

Hypertension Unit, Avicenne Hospital - AP-HP and Paris XIII University Bobigny, France
Correspondence: Jean-Jacques Mourad Avicenne University Hospital Hypertension Unit, 125 rue de Stalingrad, 93000 Bobigny cx 09, France

$\mathrm{Tel}+33$ I 48955 I 4 I

Fax +33 I 48955668 Email jean-jacques.mourad@avc. ap-hop-paris.fr

\begin{abstract}
Elevated blood pressure is an important cardiovascular risk factor. Although targets for both diastolic blood pressure (DBP) and systolic blood pressure (SBP) are defined by current guidelines, DBP has historically taken precedence in hypertension management. However, there is strong evidence that $\mathrm{SBP}$ is superior to DBP as a predictor of cardiovascular events. Moreover, achieving control of SBP is assuming greater importance amongst an aging population. In spite of the growing recognition of the importance of SBP in reducing cardiovascular risk and the emphasis by current guidelines on SBP control, a substantial proportion of patients still fail to achieve SBP targets, and SBP control is achieved much less frequently than DBP control. Thus, new approaches to the management of hypertension are required in order to control SBP and minimize cardiovascular risk. Fixed-dose combination (FDC) therapy is an approach that offers the advantages of multiple drug administration and a reduction in regimen complexity that favors compliance. We have reviewed the latest evidence demonstrating the efficacy in targeting SBP of the most recent FDC products; combinations of the calcium channel blocker (CCB), amlodipine, with angiotensin receptor blockers (ARBs), valsartan or olmesartan. In addition, results from studies with new classes of agent are outlined.
\end{abstract}

Keywords: hypertension, systolic blood pressure, angiotensin receptor blocker, calcium channel blocker, combination therapy

\section{Introduction}

Numerous studies have shown that elevated blood pressure (BP) is a major risk factor for cardiovascular morbidity and mortality. This relationship, which has been demonstrated in a range of patient populations and age groups, is strong and continuous (Kannel et al 1971; MacMahon et al 1990; Stamler et al 1993; Adler et al 2000; Staessen et al 2000; Padwal et al 2001; Lewington et al 2002).

Blood pressure is a continuous variable with a normal distribution in the population (Padwal et al 2001; Chobanian et al 2003). Thus, by necessity, any definition of 'hypertension' is arbitrary. However, there is a consensus among many of the major guidelines for the treatment of hypertension that individuals with a BP $\geq 140 / 90 \mathrm{mmHg}$ should be regarded as hypertensive, and that attempts should be made to keep BP below this threshold in all individuals (Chobanian et al 2003; Whitworth 2003; National Collaborating Centre for Chronic Conditions 2006; Mancia et al 2007). Systolic and diastolic BP targets are generally lower in patients at high cardiovascular risk and in those with diabetes or renal disease (Chobanian et al 2003; Whitworth 2003; Mancia et al 2007).

Diastolic BP (DBP) has historically taken precedence over systolic BP (SBP) in the treatment of hypertension. This situation has arisen because early epidemiological and 
interventional trials focused primarily on the risks associated with DBP (Black 2004), a focus that has influenced subsequent clinical practice. However, a number of large, well-validated studies have shown that SBP is a better predictor of cardiovascular risk than DBP in most of the subjects allocated to chronic antihypertensive therapy in clinical practice. In addition to these observations, the increase in life expectancy observed over the last few decades in many developed countries means that the paradigm has shifted towards SBP (Black 2004).

Elevations in SBP frequently occur without elevations in DBP, a condition known as 'isolated systolic hypertension' (ISH: SBP $\geq 140 \mathrm{mmHg}$, DBP $<90 \mathrm{mmHg}$ ) (Chobanian et al 2003). Arterial stiffness, endothelial dysfunction, atherosclerosis, and oxidative stress all contribute to the development of ISH, which is the predominant type of hypertension in elderly patients (Thijs et al 2004; Wallace et al 2007). Since DBP is, by definition, normal in patients with ISH, aggressive lowering of DBP may not be an appropriate strategy for this patient group. Moreover, until recently, the development of new antihypertensive agents has focused almost exclusively on mechanisms that lead to decreased DBP, and drugs developed as a result of this strategy may not provide optimal management of elevated SBP. Drugs that have proven to be particularly useful in the treatment of ISH are nitrates, calcium channel blockers (CCBs) and agents that target the renin-angiotensin system (RAS, ie, angiotensin II receptor blockers [ARBs] and angiotensin converting enzyme inhibitors [ACEIs]) because these agents improve the large artery stiffness and early wave reflection that are major characteristics of this condition (Franklin 2000).

\section{Importance of systolic blood pressure}

The importance of SBP as a predictor of cardiovascular risk has been demonstrated in a number of studies. This can be clearly seen in the classic meta-analysis of data from 61 prospective observational studies that involved almost $1,000,000$ individuals with no vascular disease at baseline carried out (Lewington et al 2002). This analysis calculated the effect of a $20 \mathrm{mmHg}$ difference in usual SBP on the risk of stroke and ischemic heart disease (IHD). The authors found that for individuals between the ages of 40 and 89 years, a usual SBP value that was lower by $20 \mathrm{mmHg}$ was associated with significantly lower risk of death from stroke (hazard ratios, 0.36-0.67) and IHD (0.49-0.67) (Lewington et al 2002).

The importance of SBP as a predictor of outcome has also been demonstrated by the Blood Pressure Lowering Treatment Trialists' Collaboration in a study involving data from over
160,000 patients enrolled in placebo- and active-controlled randomized trials of antihypertensive treatment (Turnbull 2003). This overview showed that the risks of stroke, major cardiovascular events, coronary heart disease (CHD), cardiovascular mortality, and total mortality were related to differences between treatments in SBP (Turnbull 2003). Similar results were obtained by Staessen et al $(2001,2003)$ in two meta-analyses that examined the relationship between odds ratios for cardiovascular outcomes and differences in SBP among different antihypertensive agents (Staessen et al 2001, 2003). The results of both meta-analyses led to the conclusion that differences in cardiovascular outcome can largely be attributed to differences in SBP (Figure 1).

The three studies discussed above (Turnbull 2003; Staessen et al 2001, 2003) involved analysis of data from hypertensive patients with varying degrees of cardiovascular risk. However, the importance of SBP as a cardiovascular risk factor has also been demonstrated in subgroups of patients at particularly high risk, including those with type 2 diabetes. For example, in the United Kingdom Prospective Diabetes Study, each $10 \mathrm{mmHg}$ reduction in usual SBP was associated with a significant $11 \%$ reduction in the risk of myocardial infarction (Adler et al 2000).

These data demonstrate the strong association between SBP and cardiovascular risk. However, epidemiological data and demographic shifts also serve to emphasize the importance of SBP in the current management of hypertension. For example, data from the 2003-2004 National Health and Nutrition Examination Survey (NHANES) show that ISH is the most common type of hypertension among individuals at high cardiovascular risk (those with pre-existing CVD or with comorbidities that predispose to CVD) (Wong et al 2007). Moreover, SBP is known to increase gradually with age whereas DBP tends to decrease in elderly individuals (Black 2004). Isolated systolic hypertension is thus likely to become increasingly prevalent since aging of the population is a feature of both developed and developing countries (Kalache and Keller 2000). Isolated systolic hypertension is associated with a high risk of cardiovascular events such as stroke (SHEP 1991; Staessen et al 1997; Liu et al 1998; Inoue et al 2007), and the incidence of such complications can be significantly reduced by effective antihypertensive treatment (SHEP 1991; Staessen et al 1997, 2000; Liu et al 1998; Waeber 2003). Approximately 281,000 unnecessary cardiovascular events could be prevented, with a healthcare system cost saving of $€ 1.26$ billion (based upon 2002 costing), if the BP of all patients with hypertension in five European countries (France, Germany, Italy, Sweden, and the United Kingdom) was reduced to $<140 / 90 \mathrm{mmHg}$ 
All cardiovascular events
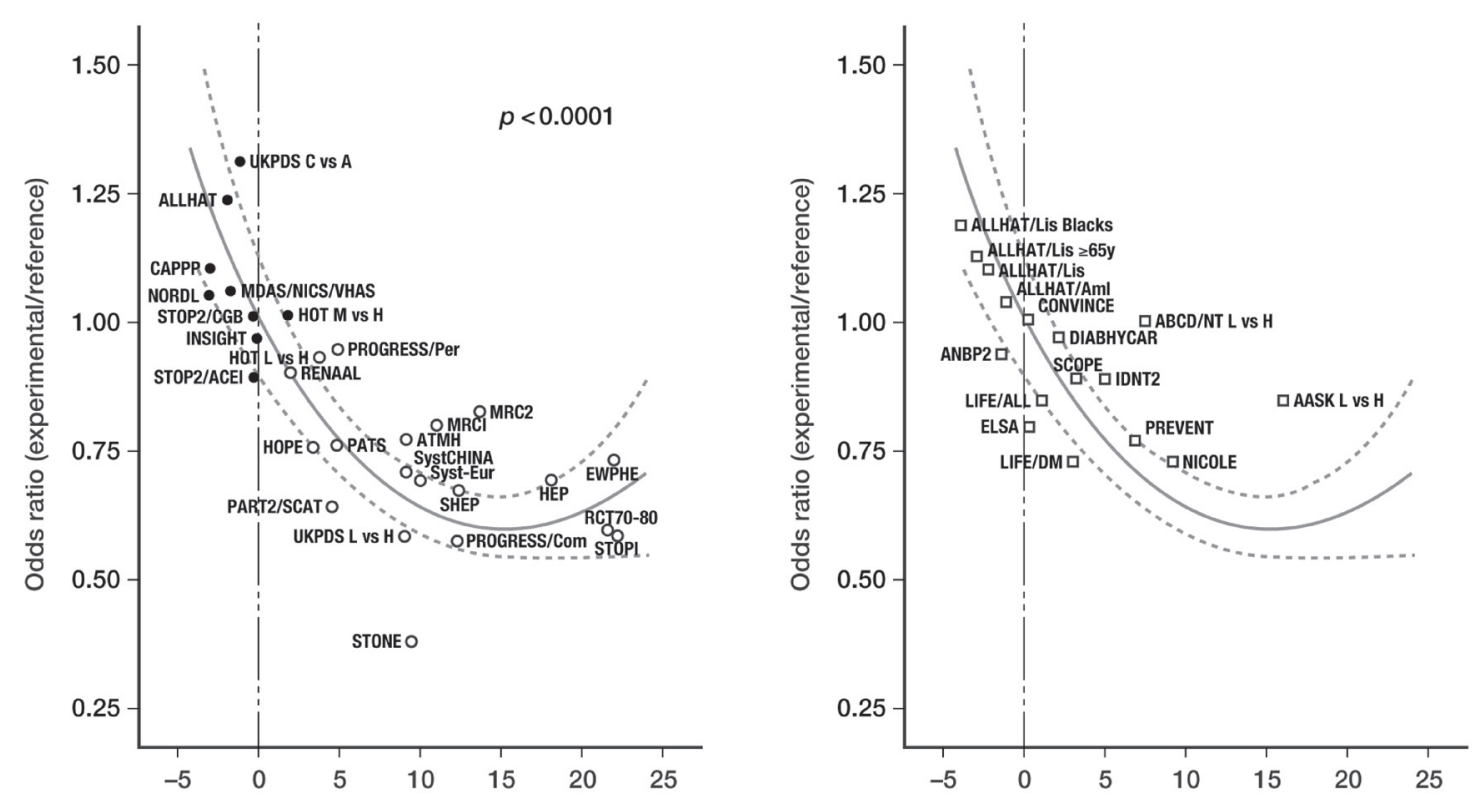

Difference (reference minus experimental) in systolic pressure $(\mathrm{mmHg})$

Figure I Relationship between odds ratios for cardiovascular events and corresponding differences in systolic blood pressure. Reprinted with permission from Staessen JA,Wang JG, Thijs L. 2003. Cardiovascular prevention and blood pressure reduction: a quantitative overview updated until I March 2003.J Hypertens, 21:I055-76. Copyright (C) 2003 Lippincott Williams \& Wilkins. The left-hand panel shows the relationship between odds ratios for cardiovascular events (experimental treatment versus reference treatment) and differences between treatments in achieved systolic blood pressure using data from clinical trials of antihypertensive drugs.The meta-regression line, which is shown with its $95 \%$ confidence interval, was weighted for the inverse of the variance of the individual odds ratios. The right-hand panel shows the results of more recent trials superimposed on the meta-regression line. Abbreviations: AASK, the African American Study of Kidney disease and hypertension; ABCD/NT, Appropriate Blood Pressure Control in Diabetes trial - tight versus usual blood pressure control in normotensive patients; ALLHAT, Antihypertensive and Lipid- Lowering Treatment to Prevent HeartAttack Trial; ALLHAT/Aml, Antihypertensive and LipidLowering treatment to prevent Heart Attack Trial - amlodipine versus chlorthalidone; ALLHAT/Lis, Antihypertensive and Lipid-Lowering treatment to prevent Heart Attack Trial - lisinopril versus chlorthalidone; ANBP2, Australian comparative outcome trial of angiotensin-converting enzyme inhibitor- and diuretic-based treatment of hypertension in the elderly; ATMH, Australian Trial in Mild Hypertension; CAPPP, CAptopril Prevention Project; CONVINCE, Controlled ONset Verapamil INvestigation of Cardiovascular Endpoints Trial; DIABHYCAR, the non-insulin-dependent DIAbetes, HYpertension, microalbuminuria or proteinuria, Cardiovascular events, and ramipril study; ELSA, European Lacidipine Study on Atherosclerosis; EWPHE, trial conducted by the European Working Party on High blood pressure in the Elderly; HEP, trial of Hypertension in Elderly Patients in primary care; HOPE, Heart Outcomes Prevention Evaluation study; HOT/LH, Hypertension Optimal Treatment trial - 80 versus 90 mmHg as target diastolic pressure; HOT/MH, Hypertension Optimal Treatment trial - 85 versus $90 \mathrm{mmHg}$ as target diastolic pressure; IDNT2, Irbesartan Diabetic Nephropathy Trial in patients with type-2 diabetes mellitus; INSIGHT, International Nifedipine GITS Study - Intervention as a Goal for Hypertension Treatment; LIFE/All, Losartan Intervention For Endpoint reduction in hypertension study - all patients; LIFE/DM, Losartan Intervention For Endpoint reduction in hypertension study - diabetic subgroup; MIDAS/NICS/VHAS, combined results of MIDAS, NICS and VHAS; MRCI, Medical Research Council trial of treatment of mild hypertension; MRC2, Medical Research Council trial of treatment of hypertension in older adults; NICOLE, Nlsoldipine in Coronary artery disease in LEuven; NORDIL, NOrdic DILtiazem study; PART2, Prevention of Atherosclerosis with Ramipril Trial; PART2/SCAT, combined results of PART2 and SCAT; PATS, Post-stroke Antihypertensive Treatment Study; PREVENT, Prospective Randomized Evaluation of the Vascular Effects Norvasc Trial; PROGRESS/Com, perindopril PROtection aGainst REcurrent Stroke Study - group on combined therapy; PROGRESS/Per, perindopril PROtection aGainst REcurrent Stroke Study - group on single-drug treatment; RENAAL, Reduction of Endpoints in NIDDM with the Angiotensin II Antagonist Losartan; RCT70-80, combined results of four smaller trials published from I970 through I980, including HSCS, OSLO, USPHS, and VACS; SCOPE, Study on COgnition and Prognosis in the Elderly; SHEP, Systolic Hypertension in the Elderly Program; STONE, Shanghai Trial of Nifedipine in the Elderly; STOPI, Swedish Trial in Old Patients with hypertension; STOP2/ACEls, angiotensin-converting enzyme inhibitor arm of STOP2; STOP2/CCBs, calcium-channel blocker arm of STOP2; Syst-China, Systolic hypertension in China trial; Syst-Eur, Systolic hypertension in Europe trial; UKPDS, UKPDS hypertension in diabetes study; UKPDS/CA, UKPDS hypertension in Diabetes Study - captopril versus atenolol; UKPDS/LH, UKPDS hypertension in diabetes study - low versus high on-treatment blood pressure.

(Hansson et al 2002). The predominance of ISH in elderly hypertensive patients is likely to explain the observation that the importance of SBP as a predictor of CHD risk increases with age (Kannel et al 1971).

\section{Superior prediction of cardiovascular risk with systolic blood pressure}

Nearly 40 years ago, data from the Framingham Heart Study showed that SBP was more closely associated with risk of
CHD than DBP (Kannel et al 1971). Although DBP was shown to be a more useful predictor of risk in hypertensive patients under 45 years old, for the majority of hypertensive patients, the ability of SBP to predict CHD was not improved by addition of DBP data (Kannel et al 1971). The superior predictive ability of SBP was more recently confirmed by the Prospective Studies Collaboration, a meta-analysis of 61 prospective observational studies that recorded BP and cause-specific mortality (Lewington et al 2002). In this study, Lewington et al (2002) found that SBP at baseline was more informative than DBP as a predictor of stroke 
and IHD mortality. Moreover, the study concluded that, in middle-aged individuals, prolonged reductions in usual SBP of only $2 \mathrm{mmHg}$ would lead to substantial reductions in the incidence of death secondary to stroke ( $7 \%$ reduction) and IHD or other vascular causes (10\%) (Lewington et al 2002).

These findings are supported by those of Stamler et al (1993) who found that SBP had a stronger association with cardiovascular risk than DBP in middle-aged and elderly individuals. At every level of DBP in this population, a higher SBP value was associated with greater cardiovascular risk and lower life expectancy (Stamler et al 1993). The results of one study, however, demonstrated that gender may be an important factor in determining the extent to which DBP also plays a role in cardiovascular risk in middle-aged patients (Benetos et al 2001). In this study, although SBP was strongly associated with mortality both in men and women, DBP was also an important predictive factor, but only in women (Benetos et al 2001).

More recently, Benetos et al (2003) aimed to determine whether the high cardiovascular mortality rate of treated hypertensive patients was due to hypertension or to the presence of associated risk factors and/or diseases. Using cardiovascular mortality data from treated hypertensive patients $(\mathrm{n}=8893)$ and from untreated age- and gender-matched normotensive and hypertensive controls $(n=25,880)$ enrolled in the Investigations Préventives et Cliniques cohort, Benetos et al (2003) found that the two-fold increase in cardiovascular and coronary mortality that was apparent in treated hypertensive patients persisted after adjustment for cardiovascular risk factors. Adjustment for SBP was necessary to render the mortality rates similar in the two populations. Subsequent inclusion of DBP in the model did not modify the between-group risk ratio. These results indicate that the increased cardiovascular mortality in treated hypertensive patients is mainly due to uncontrolled SBP levels (Benetos et al 2003) (Figure 2).

Systolic BP is also superior to DBP as a predictor of adverse renal outcomes in patients with diabetic nephropathy. Pohl et al (2005) used data from 1590 hypertensive, diabetic patients enrolled in the Irbesartan Diabetic Nephropathy Trial to determine the effects of treatment allocation (irbesartan, amlodipine, or placebo), and baseline and mean follow-up SBP and DBP on progressive renal failure and all-cause mortality. Pohl et al (2005) found that follow-up achieved SBP was the strongest predictor of an adverse renal outcome (doubling of serum creatinine or progression to end-stage

\section{- Unadjusted}

\section{$\square$ Adjusted for SBP}

Adjusted for SBP and

DBP

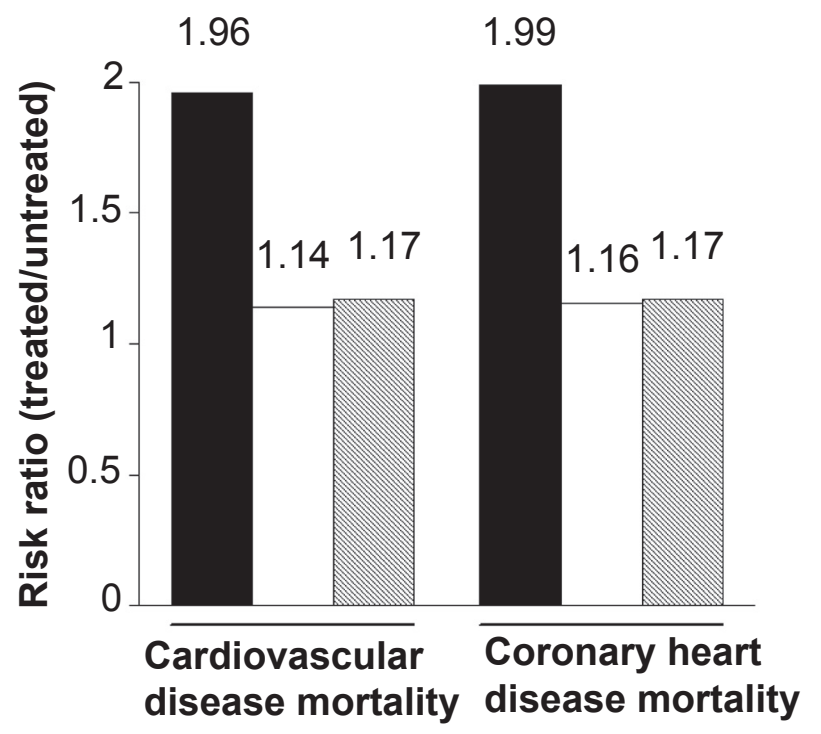

Figure 2 Risk ratios for mortality as a result of cardiovascular disease and coronary heart disease in patients treated for hypertension compared with gender- and age-matched hypertensive and normotensive subjects (Derived from Benetos et al 2003).

Benetos et al (2003) used data from 8893 treated hypertensive patients and 25,880 untreated age- and gender-matched normotensive and hypertensive control patients to determine the influence of hypertension on cardiovascular mortality. Cardiovascular and coronary mortality were two-fold higher in the treated population. After adjustment for systolic blood pressure (SBP) using Cox regression analysis, the differences between the treated and untreated populations decreased from $96 \%$ to $14 \%$ (cardiovascular mortality, $\mathrm{P}=0.05$ ) and from $99 \%$ to $16 \%$ (coronary heart disease mortality, $P=0.08$ ). Subsequent adjustment for diastolic blood pressure (DBP) had no further effect on the risk ratios.

renal disease). Moreover, the risk associated with inadequate control of SBP was substantial. Compared with patients who achieved SBP values $<134 \mathrm{mmHg}$, those with SBP levels $>149 \mathrm{mmHg}$ had more than twice the risk of a renal endpoint. Also, values of baseline and achieved SBP that were lower by $20 \mathrm{mmHg}$ were associated with relative risks of 0.79 and 0.52 , respectively (Table 1 ). In contrast, there was no relationship between baseline or achieved DBP and progression of renal disease (Table 1) (Pohl et al 2005). Lowering of SBP was also associated with reduced risk of death. However, although the beneficial effects of lowering SBP were graded and continuous down to a level of $120 \mathrm{mmHg}$, the association with adverse renal outcomes showed evidence of a plateau below this level. Moreover, all-cause mortality showed a sharp increase at achieved SBP levels $\leq 120 \mathrm{mmHg}$ (Pohl et al 2005). Pohl et al (2005) concluded that a SBP target between $120 \mathrm{mmHg}$ and $130 \mathrm{mmHg}$ seems ideal in this population. 
Table I Impact of systolic and diastolic blood pressure on risk of an adverse renal outcome (doubling of serum creatinine or progression to end stage renal disease) (Reproduced with permission from Pohl MA, Blumenthal S, Cordonnier DJ, et al. 2005. Independent and additive impact of blood pressure control and angiotensin II receptor blockade on renal outcomes in the irbesartan diabetic nephropathy trial: clinical implications and limitations. J Am Soc Nephrol, 16:3027-37. Copyright @ 2005 American Society of Nephrology).

\begin{tabular}{llll}
\hline & RR & $95 \%$ Cl & P value \\
\hline Baseline & & & \\
SBP lower by $20 \mathrm{mmHg}$ & 0.79 & $0.71,0.88$ & $<0.000$ । \\
$\begin{array}{l}\text { DBP lower by } 20 \mathrm{mmHg} \\
\text { Achieved }\end{array}$ & 1.02 & $0.85,1.22$ & 0.86 \\
$\quad$ & & \\
SBP lower by $20 \mathrm{mmHg}$ & 0.52 & $0.45,0.60$ & $<0.000$ । \\
DBP lower by $20 \mathrm{mmHg}$ & $\mathrm{I} .06$ & $0.84,1.35$ & 0.61 \\
\hline
\end{tabular}

Notes: Relative risks were computed by applying Cox proportional hazards methods to data from 1590 hypertensive patients with type 2 diabetes who were randomized to one of three antihypertensive treatment regimens (irbesartan $300 \mathrm{mg} /$ day, amlodipine $10 \mathrm{mg} /$ day, or placebo). Median patient follow-up was 2.6 years.

Abbreviations: $\mathrm{Cl}$, confidence interval; DBP, diastolic blood pressure; RR, relative risk; SBP, systolic blood pressure.

It is evident from the data described above that SBP is a more useful predictor of cardiovascular and renal events than DBP, although DBP should also be taken into consideration in younger patients and in women. Achievement of SBP targets should thus be given priority in the majority of patients receiving antihypertensive therapy.

\section{Achievement of systolic blood pressure targets}

In spite of the growing recognition that adequate control of SBP is fundamental to reducing cardiovascular risk, a substantial proportion of patients still fail to achieve the target levels defined by current guidelines. For example, data from NHANES III show that SBP was controlled to $<140 \mathrm{mmHg}$ in only $34 \%$ of hypertensive patients (treated or untreated) (Franklin et al 2001). In contrast, $73 \%$ of patients achieved DBP control $(<90 \mathrm{mmHg})$. More recent NHANES data (2003-2004) have shown that hypertensive patients who are receiving treatment but who are not at goal tend to be $\geq 20 \mathrm{mmHg}$ above their SBP target, and $<10 \mathrm{mmHg}$ above their DBP target (Wong et al 2007). This situation is not restricted to the United States. The Evaluation and Interventions for Systolic Blood Pressure Elevation - Regional and Global (EISBERG) project, which analyzed data from more than 17,000 patients in seven countries (Canada, France, Germany, Italy, Spain, United Kingdom, and the United States), found that a substantially higher percentage of patients had DBP controlled to levels endorsed by national guidelines than SBP (Swales 1999).

Such differences may result, in part at least, from the attitude of physicians, who tended to set less rigorous targets for SBP than DBP. A similar bias was reported in the Hypertension and Diabetes Screening and Awareness (HYDRA) study, which analyzed data from 45,125 primary care patients in Germany (Steckelings et al 2004). In this study, elevated SBP levels were tolerated by doctors in $51 \%$ of affected patients. In contrast, elevated DBP levels were tolerated in only $41 \%$ of affected patients.

One might expect the situation to be better in intervention trials, where patient motivation and compliance are likely to be high, and the protocol is likely to emphasize achievement of target BP. However, even under these conditions, control of DBP is achieved more frequently than SBP control. For example, in the Antihypertensive and Lipid-Lowering Treatment to Prevent Heart Attack Trial (ALLHAT), 67\% of patients achieved SBP $<140 \mathrm{mmHg}$, whereas $92 \%$ achieved DBP $<90 \mathrm{mmHg}$ (Cushman et al 2002). Overall control $(<140 / 90 \mathrm{mmHg})$ was recorded in $66 \%$ of patients. Similar results were reported from the Controlled ONset Verapamil INvestigation of Cardiovascular Endpoints (CONVINCE) study, in which $69 \%-71 \%$ and $90 \%$ of patients maintained control of SBP and DBP, respectively (Black et al 2001). As in ALLHAT, overall control - which occurred in $67 \%-69 \%$ of patients - was similar to the proportion of patients who achieved control of SBP.

These results from individual studies are confirmed by those of Mancia and Grassi (2002) who used data from 10 controlled trials to show that far fewer patients achieve the level of SBP control recommended by guidelines than achieve the recommended DBP level (Figure 3). Overall, DBP $<90 \mathrm{mmHg}$ and SBP $<140 \mathrm{mmHg}$ were achieved by approximately $90 \%$ and $50 \%$ of treated patients, respectively (Mancia and Grassi 2002). Control of SBP and DBP was even worse among patients with diabetes. However, although the mean achieved DBP level was lower than the target in a number of studies involving diabetic patients, in no study did the mean achieved SBP level reach its target.

The relatively poor control of SBP identified in clinical trials is also apparent in specialist clinics and primary care practice. For example, in a specialist hypertension clinic that documented the effects of managing patients using a 'goal oriented' approach, $63 \%$ and $86 \%$ of patients achieved SBP $<140 \mathrm{mmHg}$ and DBP $<90 \mathrm{mmHg}$, respectively (Singer et al 2002). Achieving the level of BP control that is recommended for patients with diabetes proved particularly 

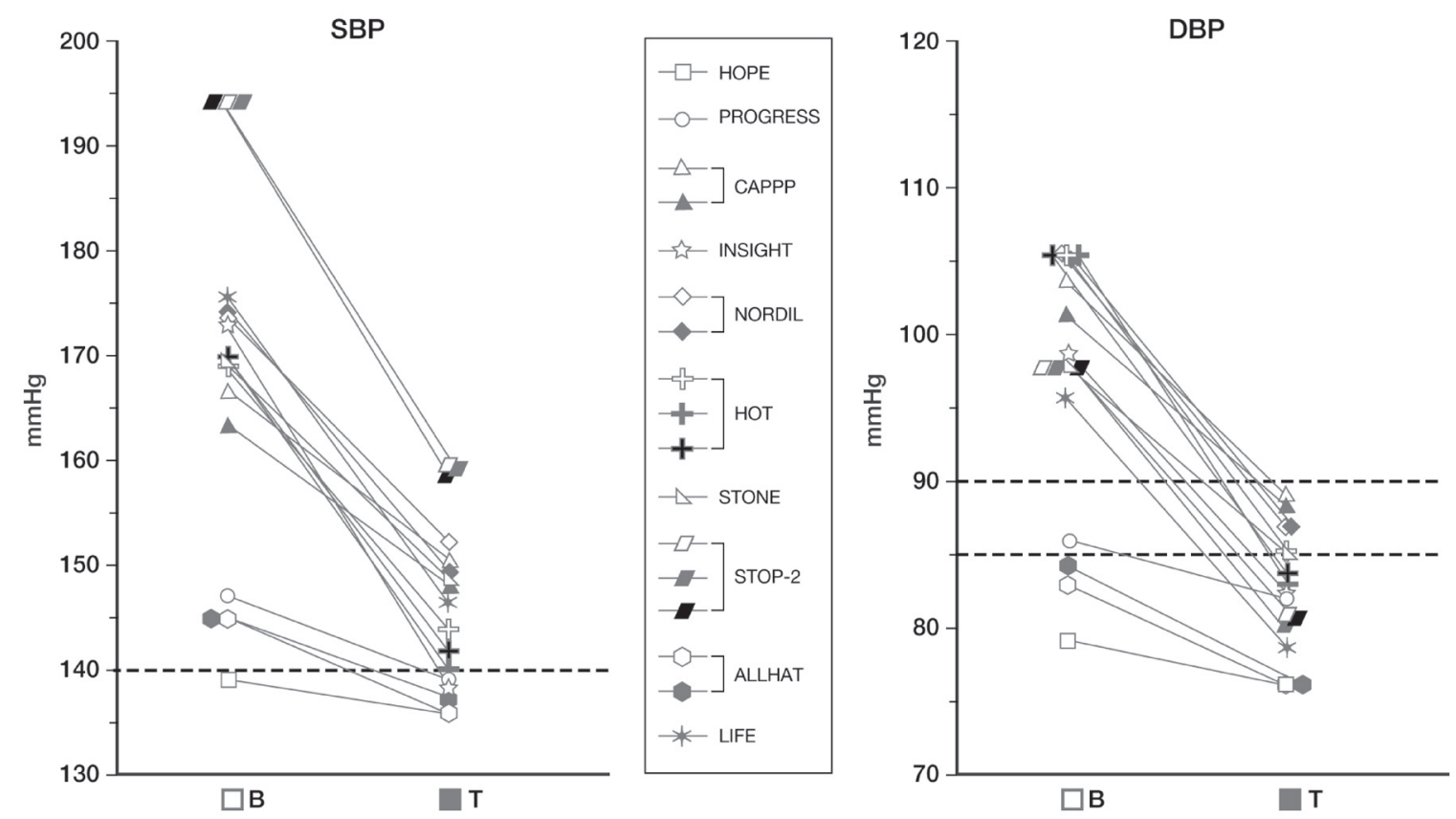

Figure 3 Achievement of blood pressure goals in controlled trials of antihypertensive agents. Reproduced with permission from Mancia G, Grassi G. 2002. Systolic and diastolic blood pressure control in antihypertensive drug trials.J Hypertens, 20:146|-4. Copyright (C) 2002 Lippincott Williams \&Wilkins.

Mancia and Grassi (2002) summarized the effects of antihypertensive treatment on systolic and diastolic blood pressure (SBP and DBP, respectively) in clinical trials involving patients with essential hypertension. The data show that higher initial blood pressures $(\mathrm{B})$ are associated with larger reductions during treatment ( $\mathrm{T}$ ). Target blood pressure values (SBP, $140 \mathrm{mmHg}$; DBP, 85-90 mmHg), shown as dotted lines on the graphs, were achieved more frequently for DBP than for SBP. See Figure I legend for key to trial names.

difficult. Only $23 \%$ of this group achieved the Joint National Committee on Detection, Evaluation, and Treatment of High Blood Pressure (JNC) VI SBP goal (Joint National Committee 1997) for this population of $<130 \mathrm{mmHg}$ whereas $68 \%$ achieved their DBP goal $(<85 \mathrm{mmHg})$ (Singer et al 2002). Similar findings have been reported from primary care. For example, in the HYDRA study, $95 \%$ of patients with uncontrolled hypertension had elevated SBP levels (Steckelings et al 2004). In contrast, DBP was elevated in only $50 \%$ of patients.

The consistent difference in the levels of SBP and DBP control achieved in interventional trials, specialist hypertension clinics, and primary practice suggests that controlling SBP is substantially more difficult than controlling DBP. Achieving overall control of BP in patients with ISH is thus particularly challenging. Moreover, SBP must be controlled in this population without excessive lowering of DBP $(\leq 60 \mathrm{mmHg})$, because this degree of DBP reduction has been associated with reduced survival (Protogerou et al 2007). This point is probably of particular importance in specific populations, such as diabetic patients, subjects with overt coronary artery disease and elderly hypertensives in whom attempted lowering of SBP to target levels of less than $130 \mathrm{mmHg}$ is often associated with inordinate lowering of DBP that could lead to an excess in coronary ischemic events (Messerli et al 2006; Peralt et al 2007 Osher and Stern 2008).

\section{Systolic blood pressure in hypertension guidelines}

Current guideline recommendations represent a paradigm shift towards SBP. This change of emphasis has been influenced by the increase in human life expectancy (Kalache and Keller 2000), by the results of numerous analyses showing that SBP is a better predictor of cardiovascular risk than DBP (Kannel et al 1971; Stamler et al 1993; Lewington et al 2002; Benetos et al 2003; Black 2004), and by recognition that poor control of SBP is largely responsible for the prevailing low rates of BP control (Lloyd-Jones et al 2000; Hyman and Pavlik 2001). These factors have led to emphasis of the importance of SBP as a cardiovascular risk factor in the current treatment guidelines of the JNC VII and the World Health Organization/International Society of Hypertension (WHO-ISH) (Chobanian et al 2003; Whitworth 2003). Indeed, for patients at low-to-medium risk, the WHO/ISH guidelines recommend a target for SBP only $(<140 \mathrm{mmHg})$. This approach is justified by evidence from the STRAtegies of Treatment in Hypertension: Evaluation (STRATHE) study which showed that 
$\mathrm{SBP} \leq 140 \mathrm{mmHg}$

$\mathrm{DBP} \geq 90 \mathrm{mmHg}$

$\mathrm{SBP} \geq 140 \mathrm{mmHg}$

$\mathrm{DBP} \leq 90 \mathrm{mmHg}$

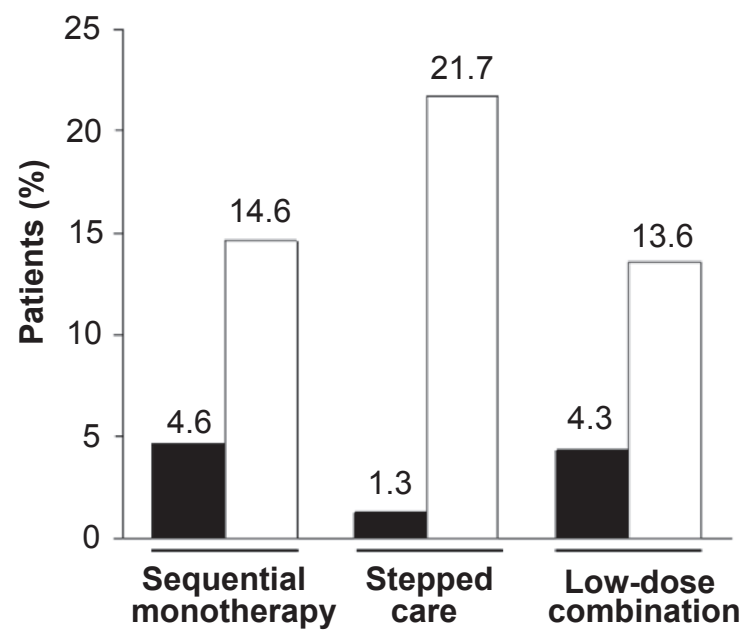

Figure 4 Percentage of patients who achieved SBP $<140 \mathrm{mmHg}$ and retained $\mathrm{DBP} \geq 90 \mathrm{mmHg}$ compared with percentage of patients who achieved DBP $<90 \mathrm{mmHg}$ and retained SBP $\geq 140 \mathrm{mmHg}$. Reproduced with permission from Waeber B, Mourad J]. 2006. Targeting systolic blood pressure: the key to controlling combined systolic/diastolic hypertension. Am J Hypertens, 19:985-6. Copyright (C 2006 Nature Publishing Group. Data from the STRAtegies of reatment in Hypertension: Evaluation (STRATHE) study show that patients who achieve a target systolic blood pressure (SBP) $<140 \mathrm{mmHg}$ are also likely to achieve a diastolic blood pressure $<90 \mathrm{mmHg}$. In contrast, a substantial proportion of patients who achieve DBP $<90 \mathrm{mmHg}$ fail to achieve adequate control of SBP.As demonstrated by the figure, this finding is consistent across a range of treatment regimens.

if SBP goals are achieved, DBP goals are also likely to be realized. For example, in the STRATHE study, only $3.4 \%$ of treated patients with stage 2 hypertension who achieved a $\mathrm{SBP}<140 \mathrm{mmHg}$ retained a $\mathrm{DBP} \geq 90$ mmHg (Waeber and Mourad 2006). In contrast, 16.6\% of patients who achieved a DBP $<90 \mathrm{mmHg}$ retained a $\mathrm{SBP} \geq 140 \mathrm{mmHg}$ (Figure 4).

\section{New approaches in hypertension management}

Despite the fact that the literature shows that SBP is an extremely important target for blood pressure lowering, many physicians remain driven by target achievement for DBP. Hypertension thus remains poorly controlled. However, there have been changes in understanding of the necessary treatment algorithm and it is now well recognized that most patients will require combination therapy, initiated as first line or at least early, to achieve guideline BP targets (Mancia et al 2007). However, there is an inverse relationship between regimen complexity and patient adherence (Osterberg and Blaschke 2005; Fung et al 2007), and treatment regimens that involve administration of multiple drugs have consistently been associated with reduced compliance and adherence (Payne and Esmonde-White 2000; Fung et al 2007). The use of fixed-dose combinations represents an alternative approach to multiple drug therapy that has been shown to improve patient adherence (Elliott 2002; Bangalore et al 2007). They also offer the possibility to combine agents with different pharmacological profiles to achieve additive effects with enhanced tolerability. The approach of using fixed-dose combinations as first-line treatment or earlier in patients with comorbidities that require rapid blood pressure reduction is endorsed by current guidelines (Chobanian et al 2003; Mancia et al 2007).

A number of fixed-dose combination therapies are already in clinical use. These include ACEI/CCB (Jamerson et al 2004; Roca-Cusachs et al 2008), ACEI/diuretic (Mourad et al 2007; Patel et al 2007), and ARB/diuretic (Lacoucière et al 2005; Ruilope et al 2005; Neutel et al 2006). There are also fixed-dose combinations involving $\beta$-blockers, although the finding that $\beta$-blockers may be less effective for stroke prevention than other antihypertensive agents (Lindholm et al 2005) has led to a trend towards guidelines placing less prominence on $\beta$-blocker-based therapy (National Collaborating Centre for Chronic Conditions 2006; Mancia et al 2007).

While there is a paucity of comparative data on the various combinations, the recent results from the Avoiding Cardiovascular Events in Combination Therapy in Patients Living with Systolic Hypertension (ACCOMPLISH) trial (Jamerson et al 2008) gives an insight into the effectiveness of combinations involving CCB relative to those involving a diuretic. The results demonstrated that fixed-dose ACEI/CCB combination therapy significantly reduced the risk of morbidity and mortality relative to ACEI/diuretic therapy, despite similar BP reductions. It is unclear to what extent these findings are relevant to other fixed-dose combinations containing diuretic or CCBs; however, it would seem to support the use of fixed-dose combination therapy involving an agent acting on the RAS, and a CCB in hypertensive patients at high risk of developing coronary ischemic events.

A new strategy that will add to currently available treatment options is a fixed-dose combination of an ARB with the widely used CCB amlodipine. This promising new approach to treatment is currently represented by olmesartan medoxomil/amlodipine besylate and valsartan/ amlodipine fixed-dose combinations. Aliskiren, an oral renin inhibitor, represents another approach to the management of 
Table 2 Reductions in systolic and diastolic blood pressure achieved with aliskiren monotherapy and with amlodipine/valsartan, amlodipine/olmesartan, and aliskiren/hydrochlorothiazide combination therapy regimens

\begin{tabular}{|c|c|c|c|c|c|c|c|c|}
\hline \multirow[t]{2}{*}{$\begin{array}{l}\text { Daily treatment } \\
\text { regimen }\end{array}$} & \multirow[t]{2}{*}{$\begin{array}{l}\text { Seated DBP } \\
\text { inclusion criteria } \\
(\mathrm{mmHg})\end{array}$} & \multirow[t]{2}{*}{$\mathbf{n}$} & \multirow[t]{2}{*}{$\begin{array}{l}\text { Mean age } \\
\text { (years) }\end{array}$} & \multirow[t]{2}{*}{$\begin{array}{l}\text { Mean seated } \\
\text { BP at baseline } \\
(\mathrm{mmHg})\end{array}$} & \multirow[t]{2}{*}{$\begin{array}{l}\text { Duration of } \\
\text { treatment } \\
\text { (weeks) }\end{array}$} & \multicolumn{2}{|c|}{$\begin{array}{l}\text { Mean reduction } \\
\text { from baseline } \\
\text { in seated BP } \\
(\mathrm{mmHg})\end{array}$} & \multirow[t]{2}{*}{ Reference } \\
\hline & & & & & & SBP & DBP & \\
\hline $\begin{array}{l}\text { Amlodipine }(10 \mathrm{mg}) / \\
\text { valsartan (160 mg) }\end{array}$ & $\geq 95$ and $<110$ & 209 & 56.7 & I57.4/99.3 & 8 & $27.8^{\mathrm{a}}$ & $17.6^{\mathrm{a}}$ & $\begin{array}{l}\text { Philipp et al } \\
2007\end{array}$ \\
\hline $\begin{array}{l}\text { Amlodipine }(5-10 \mathrm{mg}) / \\
\text { valsartan }(160 \mathrm{mg})\end{array}$ & $\geq 110$ and $<120$ & 64 & 56.5 & $170.8 / 1 \mid 2.2$ & 6 & 35.8 & 28.6 & $\begin{array}{l}\text { Poldermans } \\
\text { et al } 2007\end{array}$ \\
\hline $\begin{array}{l}\text { Amlodipine }(10 \mathrm{mg}) / \\
\text { olmesartan }(40 \mathrm{mg})\end{array}$ & $95-120$ & 162 & 54.1 & $165.7 / 102.4$ & 8 & 30.1 & 19.0 & $\begin{array}{l}\text { Chrysant } \\
\text { et al } 2008\end{array}$ \\
\hline Aliskiren $(\mathrm{I} 50 \rightarrow 300 \mathrm{mg})^{\mathrm{b}}$ & $95-109$ & 560 & NR & NR & 12 & 17.4 & 12.2 & $\begin{array}{l}\text { Schmieder } \\
\text { et al } 2007\end{array}$ \\
\hline $\begin{array}{l}\text { Aliskiren }(300 \mathrm{mg}) / \\
\text { HCTZ ( } 25 \mathrm{mg})\end{array}$ & $95-109$ & 173 & 54.8 & I54.6/99.3 & 8 & $21.2^{\mathrm{a}}$ & $14.3^{\mathrm{a}}$ & $\begin{array}{l}\text { Villamil et al } \\
2007\end{array}$ \\
\hline
\end{tabular}

aleast squares mean; ${ }^{b}$ forced titration after 3 weeks.

Abbreviations: BP, blood pressure; DBP, diastolic blood pressure; HCTZ, hydrochlorothiazide; NR, data not reported; SBP, systolic blood pressure.

hypertension that has recently become available. Aliskiren is available as monotherapy; a fixed-dose combination with hydrochlorothiazide (HCTZ) is also available in the United States.

Given the importance of controlling SBP, it is important to consider the impact of any new therapy on this aspect of hypertension. Certainly, the studies published to date on the efficacy of ARB/amlodipine combination therapy suggest that this strategy is capable of producing substantial reductions in SBP. For example, in a randomized, double-blind, placebo-controlled, factorial study involving 1940 patients with a mean baseline seated BP level of $164 / 102 \mathrm{mmHg}$, the combination of olmesartan medoxomil ( $40 \mathrm{mg} /$ day) and amlodipine besylate ( $10 \mathrm{mg} /$ day) was associated with mean SBP reductions of $30.1 \mathrm{mmHg}$ after 8 weeks of treatment (Chrysant et al 2008) (Table 2, Figure 5).

Reductions in SBP approaching this magnitude have been reported in a registration study for valsartan/amlodipine combination therapy. The patients in this trial had less severe hypertension at baseline (mean seated BP, $156.7 / 99.1 \mathrm{mmHg}$ ) (Philipp et al 2007) than those in the olmesartan/amlodipine trial (Chrysant et al 2008) and the mean SBP reduction observed after 8 weeks of amlodipine $(10 \mathrm{mg} /$ day $) /$ valsartan (160 mg/day) was $27.8 \mathrm{mmHg}$ (Table 2) (Philipp et al 2007). This dose is equivalent to the maximal marketed dose of the drug when administered as a fixed-dose combination in Europe.

The percentage of patients who achieved their target BP was reported in each of these ARB/amlodipine studies. However, the goal criteria in the olmesartan/ amlodipine medoxomil study reflect current guideline recommendations (BP $<130 / 80 \mathrm{mmHg}$ for patients with diabetes, $<140 / 90 \mathrm{mmHg}$ for all others [Chrysant et al 2008]) and were more stringent than those defined in the valsartan/amlodipine study (DBP $<90 \mathrm{mmHg}$ or $\geq 10 \mathrm{mmHg}$ decrease from baseline [target SBP reduction not defined] [Philipp et al 2007]). This difference invalidates comparison of goal rate achievement between the two studies.

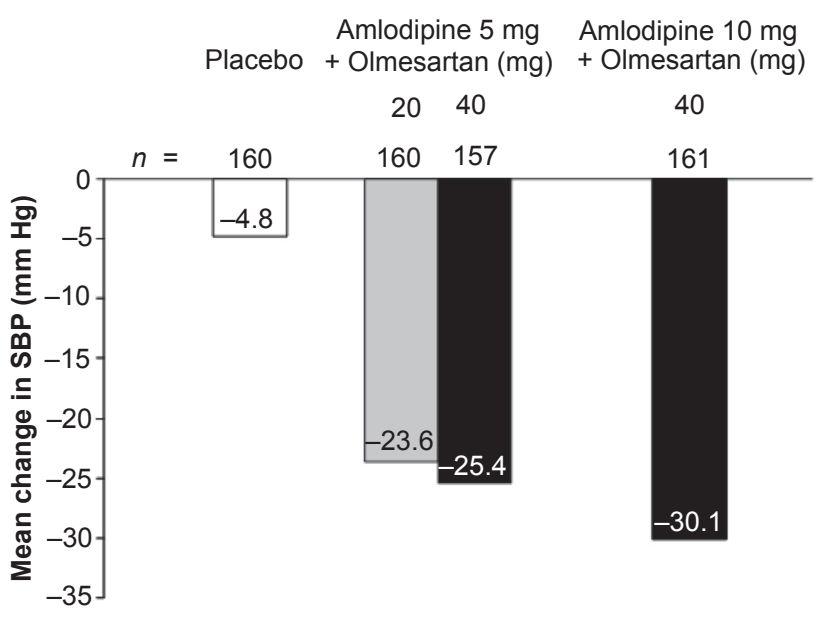

Figure 5 Systolic blood pressure reductions achieved with a combination of amlodipine and olmesartan (Chrysant et al 2008).

In the COACH study (Combination of Olmesartan medoxomil and Amlodipine besylate in Controlling High blood pressure), patients with a seated diastolic blood pressure of $95-120 \mathrm{mmHg}$ at baseline were randomized to receive daily treatment with placebo, olmesartan/amlodipine $20 / 5 \mathrm{mg}, 40 / 5 \mathrm{mg}$, or $40 / 10 \mathrm{mg}$. The figure shows the mean reduction from baseline in seated systolic blood pressure (SBP) after 8 weeks of treatment. 
Patients with severe hypertension require more substantial reductions in SBP. However, as demonstrated by Mancia and Grassi (2002) in a summary of data from 10 major clinical trials, higher initial BPs are typically associated with larger reductions during antihypertensive treatment (Figure 3 ). This concept is borne out by the results of a relatively small, recent trial involving patients with a mean baseline BP of approximately 171/112 mmHg (Poldermans et al 2007). Patients were treated for 6 weeks with amlodipine $(5-10 \mathrm{mg} /$ day $) /$ valsartan (160 mg/day) or lisinopril (10-20 mg/day)/HCTZ ( $12.5 \mathrm{mg} /$ day). The mean SBP reduction with the amlodipine regimen $(n=64)$ was $-35.8 \mathrm{mmHg}$ and with the lisinopril regimen $(n=66)$ it was $-31.8 \mathrm{mmHg}$. The proportion of patients achieving SBP goal rates were not reported, but the DBP goal of $<90 \mathrm{mmHg}$ was achieved by 79.7 and $77.3 \%$ in the amlodipine and lisinopril groups, respectively.

The results of these recent clinical trials involving ARB/ $\mathrm{CCB}$ combination therapy suggest that this therapeutic strategy offers potent lowering of BP and, in particular, substantial decreases in SBP. Given the strong association between SBP and cardiovascular risk, the advent of $\mathrm{ARB} / \mathrm{CCB}$ combinations in convenient fixed-dose formulations provides a useful tool in the management of hypertension, and the consequent reduction of cardiovascular morbidity and mortality.

The SBP and DBP reductions achieved with aliskiren, the first-in-class renin inhibitor, are rather more moderate than those achieved with the ARB/CCB combinations. A recent review of clinical trials involving this agent showed that, in studies of patients with $\mathrm{DBP} \geq 95$ and $<110 \mathrm{mmHg}$, aliskiren 150-300 mg as monotherapy or in combination with other antihypertensive agents produced reductions in SBP of between 8.7 and $21.2 \mathrm{mmHg}$, with approximately one third of these values falling between $14 \mathrm{mmHg}$ and $16 \mathrm{mmHg}$ (Frampton and Curran 2007). Table 2 shows data from the aliskiren monotherapy and combination therapy trials that demonstrated the largest reductions in SBP.

One approach that may allow targeted control of SBP in the future is the use of advanced glycation endproduct (AGE)-crosslink breakers. Advanced glycation endproducts are believed to contribute to arterial stiffening and endothelial dysfunction, both of which increase with age. In a recent study, Zieman et al (2007) showed that administration of the AGE-crosslink breaker, alagebrium, to patients with ISH was associated with improvements in endothelial function, and that this correlated with reductions in vascular fibrosis. The authors hypothesized that by reducing central arterial stiffness and vascular remodeling, these 'destiffening' agents may lower cardiovascular risk in older adults (Zieman et al 2007), however more studies are required to confirm this. Given the relationship between arterial stiffness and cognitive impairment (Hanon et al 2005), such agents may also lead to improvements in cognitive function in elderly patients. Improvements in cognitive function/reduced rate of decline in elderly patients have been suggested for CCBs and ARBs (Waeber 2003; Hanon et al 2006 Shlyakhto 2007).

\section{Conclusions}

This review has considered the importance of SBP as a predictor of cardiovascular outcome. It is evident from the data presented that SBP is a better predictor of cardiovascular risk than DBP in most of patients treated with BP lowering agents, and is therefore an appropriate target for antihypertensive therapy. This view is shared by current American and International guidelines on the management of hypertension, both of which place more emphasis on control of SBP than DBP (Chobanian et al 2003; Whitworth 2003). Fixed-dose $\mathrm{ARB} / \mathrm{CCB}$ combinations offer convenient and potent BP reduction, including powerful reduction of SBP. As a result, these combination treatments are likely to contribute substantially to reducing the risk of cardiovascular events in hypertensive patients.

\section{Acknowledgment}

We thank Jackie Campbell from Wolters Kluwer Health, who provided medical writing support on behalf of Daiichi-Sankyo Europe.

\section{Disclosures}

Professor Mourad has received consulting and/or lecture fees from Daiichi-Sankyo, as well as other companies developing antihypertensive therapies during the last 5 years.

\section{References}

Adler AI, Stratton IM, Neil HA, et al. 2000. Association of systolic blood pressure with macrovascular and microvascular complications of type 2 diabetes (UKPDS 36): prospective observational study. $B M J$, 321:412-9.

Bangalore S, Kamalakkannan G, Parkar S, et al. 2007. Fixed-dose combinations improve medication compliance: a meta-analysis. Am J Med, 120:713-9.

Benetos A, Thomas F, Bean KE, et al. 2003. Why cardiovascular mortality is higher in treated hypertensives versus subjects of the same age, in the general population. J Hypertens, 21:1635-40.

Benetos A, Thomas F, Safar ME, et al. 2000. Should diastolic and systolic blood pressure be considered for cardiovascular risk evaluation: a study in middle-aged men and women. J Am Coll Cardiol, 37:163-8.

Black HR, Elliott WJ, Neaton JD, et al. 2001. Baseline characteristics and early blood pressure control in the CONVINCE Trial. Hypertension, $37: 12-18$. 
Black HR. 2004. The paradigm has shifted to systolic blood pressure. J Hum Hypertens, 18:S3-S7.

Chobanian AV, Bakris GL, Black HR, et al. 2003. The Seventh Report of the Joint National Committee on Prevention, Detection, Evaluation, and Treatment of High Blood Pressure: the JNC 7 report. JAMA, 289:2560-72.

Chrysant SG, Melino M, Karki S, et al. 2008. The Combination of Olmesartan Medoxomil and Amlodipine Besylate in Controlling High Blood Pressure: $\mathrm{COACH}$, a randomized, double-blind, placebocontrolled, 8-week factorial efficacy and safety study. Clin Ther, 30:587-604.

Cushman WC, Ford CE, Cutler JA, et al. 2002. Success and predictors of blood pressure control in diverse North American settings: the antihypertensive and lipid-lowering treatment to prevent heart attack trial (ALLHAT). J Clin Hypertens (Greenwich), $4: 393-404$

Elliott WJ. 2002. Is fixed combination therapy appropriate for initial hypertension treatment? Curr Hypertens Rep, 4:278-85.

Frampton JE, Curran MP. 2007. Aliskiren: a review of its use in the management of hypertension. Drugs, 67:1767-92.

Franklin SS, Jacobs MJ, Wong ND, et al. 2001. Predominance of isolated systolic hypertension among middle-aged and elderly US hypertensives: analysis based on National Health and Nutrition Examination Survey (NHANES) III. Hypertension, 37:869-74.

Franklin SS. 2000. Is there a preferred antihypertensive therapy for isolated systolic hypertension and reduced arterial compliance? Curr Hypertens Rep, 2:253-9.

Fung V, Huang J, Brand R, et al. 2007. Hypertension treatment in a medicare population: adherence and systolic blood pressure control. Clin Ther, 29:972-84.

Hanon O, Haulon S, Lenoir H, et al. 2005. Relationship between arterial stiffness and cognitive function in elderly subjects with complaints of memory loss. Stroke, 36:2193-7.

Hanon O, Pequignot R, Seux ML, et al. 2006. Relationship between antihypertensive drug therapy and cognitive function in elderly hypertensive patients with memory complaints. $J$ Hypertens, 24:2101-7.

Hansson L, Lloyd A, Anderson P, Kopp Z. 2002. Excess morbidity and cost of failure to achieve targets for blood pressure control in Europe. Blood Press, 11:35-45.

Hyman DJ, Pavlik VN. 2001. Characteristics of patients with uncontrolled hypertension in the United States. N Engl J Med, 345:479-86.

Inoue R, Ohkubo T, Kikuya M, et al. 2007. Stroke risk in systolic and combined systolic and diastolic hypertension determined using ambulatory blood pressure. The Ohasama study. Am J Hypertens, 20:1125-31.

Jamerson KA, Bakris GL, Dahlöf B, et al. 2008. Avoiding cardiovascular events through combination therapy in patients living with systolic hypertension [abstract]. 57th Annual Scientific Session of the American College of Cardiology; 29 Mar 2008. abstr. 407-2.

Jamerson KA, Nwose O, Jean-Louis L, et al. 2004. Initial angiotensinconverting enzyme inhibitor/calcium channel blocker combination therapy achieves superior blood pressure control compared with calcium channel blocker monotherapy in patients with stage 2 hypertension. $\mathrm{Am}$ J Hypertens, 17:495-501.

Joint National Committee on Prevention, Detection, Evaluation, and Treatment of High Blood Pressure. 1997. The sixth report of the Joint National Committee on prevention, detection, evaluation, and treatment of high blood pressure. Arch Intern Med, 157:2413-46.

Kalache A, Keller I. 2000. The greying world: a challenge for the twenty-first century. Sci Prog, 83:33-54.

Kannel WB, Gordon T, Schwartz MJ. 1971. Systolic versus diastolic blood pressure and risk of coronary heart disease. The Framingham study. Am J Cardiol, 27:335-46.

Lacourcière Y, Poirier L, Hebert D, et al. 2005. Antihypertensive efficacy and tolerability of two fixed-dose combinations of valsartan and hydrochlorothiazide compared with valsartan monotherapy in patients with stage 2 or 3 systolic hypertension: an 8-week, randomized, double-blind, parallel-group trial. Clin Ther, 27:1013-21.
Lewington S, Clarke R, Qizilbash N, et al; Prospective Studies Collaboration. 2002. Age-specific relevance of usual blood pressure to vascular mortality: a meta-analysis of individual data for one million adults in 61 prospective studies. Lancet, 360:1903-13.

Lindholm LH, Carlberg B, Samuelsson O. 2005. Should beta blockers remain first choice in the treatment of primary hypertension? A meta-analysis. Lancet, 366:1545-53.

Liu L, Wang JG, Gong L, et al. 1998. Comparison of active treatment and placebo in older Chinese patients with isolated systolic hypertension. Systolic Hypertension in China (Syst-China) Collaborative Group. J Hypertens, 16:1823-9.

Lloyd-Jones DM, Evans JC, Larson MG, et al. 2000. Differential control of systolic and diastolic blood pressure: factors associated with lack of blood pressure control in the community. Hypertension, 36:594-9.

MacMahon S, Peto R, Cutler J, et al. 1990. Blood pressure, stroke, and coronary heart disease. Part 1, Prolonged differences in blood pressure: prospective observational studies corrected for the regression dilution bias. Lancet, 335:765-74.

Mancia G, De Backer G, Dominiczak A, et al. 2007 Guidelines for the management of arterial hypertension: The Task Force for the Management of Arterial Hypertension of the European Society of Hypertension (ESH) and of the European Society of Cardiology (ESC). Eur Heart J, 28:1462-536.

Mancia G, Grassi G. 2002. Systolic and diastolic blood pressure control in antihypertensive drug trials. J Hypertens, 20:1461-4.

Messerli FH, Mancia G, Conti CR, et al. 2006. Dogma disputed: can aggressively lowering blood pressure in hypertensive patients with coronary artery disease be dangerous? Ann Intern Med, 144:884-93.

Mourad JJ, Nguyen V, Lopez-Sublet M, et al. 2007. Blood pressure normalization in a large population of hypertensive patients treated with perindopril/indapamide combination: results of the OPTIMAX trial. Vasc Health Risk Manag, 3:173-80.

National Collaborating Centre for Chronic Conditions. 2006. Hypertension: management of hypertension in adults in primary care: partial update. London: Royal College of Physicians.

Neutel JM, Franklin SS, Oparil S, et al. 2006. Efficacy and safety of irbesartan/HCTZ combination therapy as initial treatment for rapid control of severe hypertension. J Clin Hypertens, 8:850-7.

Osher E, Stern N. 2008. Diastolic pressure in type 2 diabetes: can target systolic pressure be reached without 'diastolic hypotension'? Diabetes Care, 31:S249-54.

Osterberg L, Blaschke T. 2005. Adherence to medication. N Engl J Med, 353:487-97.

Padwal R, Straus SE, McAlister FA. 2001. Evidence based management of hypertension. Cardiovascular risk factors and their effects on the decision to treat hypertension: evidence based review. $B M J$, 322:977-80.

Patel A, MacMahon S, Chalmers J, et al. 2007. Effects of a fixed combination of perindopril and indapamide on macrovascular and microvascular outcomes in patients with type 2 diabetes mellitus (the ADVANCE trial): a randomised controlled trial. Lancet, 370:829-40.

Payne KA, Esmonde-White S. 2000. Observational studies of antihypertensive medication use and compliance: is drug choice a factor in treatment adherence? Curr Hypertens Rep, 2:515-24.

Peralta CA, Shlipak MG, Wassel-Fyr C, et al. 2007. Association of antihypertensive therapy and diastolic hypotension in chronic kidney disease. Hypertension, 50:474-80.

Philipp T, Smith TR, Glazer R, et al. 2007. Two multicenter, 8-week, randomized, double-blind, placebo-controlled, parallel-group studies evaluating the efficacy and tolerability of amlodipine and valsartan in combination and as monotherapy in adult patients with mild to moderate essential hypertension. Clin Ther, 29:563-80.

Pohl MA, Blumenthal S, Cordonnier DJ, et al. 2005. Independent and additive impact of blood pressure control and angiotensin II receptor blockade on renal outcomes in the irbesartan diabetic nephropathy trial: clinical implications and limitations. J Am Soc Nephrol, 16:3027-37. 
Poldermans D, Glazes R, Kargiannis S, et al. 2007. Tolerability and blood pressure-lowering efficacy of the combination of amlodipine plus valsartan compared with lisinopril plus hydrochlorothiazide in adult patients with stage 2 hypertension. Clin Ther, 29:279-89.

Protogerou AD, Safar ME, Iaria P, et al. 2007. Diastolic blood pressure and mortality in the elderly with cardiovascular disease. Hypertension, 50:172-80

Roca-Cusachs A, Schmieder RE, Triposkiadis F, et al. 2008. Efficacy of manidipine/delapril versus losartan/hydrochlorothiazide fixed combinations in patients with hypertension and diabetes. J Hypertens, 26:813-8.

Ruilope LM, Malacco E, Khder Y, et al. 2005. Efficacy and tolerability of combination therapy with valsartan plus hydrochlorothiazide compared with amlodipine monotherapy in hypertensive patients with other cardiovascular risk factors: the VAST study. Clin Ther, 27:578-87.

SHEP Cooperative Research Group. 1991. Prevention of stroke by antihypertensive drug treatment in older persons with isolated systolic hypertension. Final results of the Systolic Hypertension in the Elderly Program (SHEP). JAMA, 265:3255-64.

Shlyakhto E. 2007. Observational Study on Cognitive function And systolic blood pressure Reduction (OSCAR): preliminary analysis of 6-month data from $>10,000$ patients and review of the literature. Curr Med Res Opin, 23(Suppl 5):S13-8.

Singer GM, Izhar M, Black HR. 2002. Goal-oriented hypertension management: translating clinical trials to practice. Hypertension, 40:464-9.

Staessen JA, Fagard R, Thijs L, et al. 1997. Randomised double-blind comparison of placebo and active treatment for older patients with isolated systolic hypertension. The Systolic Hypertension in Europe (Syst-Eur) Trial Investigators. Lancet, 350:757-64.

Staessen JA, Gasowski J, Wang JG, et al. 2000. Risks of untreated and treated isolated systolic hypertension in the elderly: meta-analysis of outcome trials. Lancet, 355:865-72.

Staessen JA, Wang JG, Thijs L. 2001. Cardiovascular protection and blood pressure reduction: a meta-analysis. Lancet, 358:1305-15.

Staessen JA, Wang JG, Thijs L. 2003. Cardiovascular prevention and blood pressure reduction: a quantitative overview updated until 1 March 2003 J Hypertens, 21:1055-76.
Stamler J, Stamler R, Neaton JD. 1993. Blood pressure, systolic and diastolic, and cardiovascular risks. US population data. Arch Intern Med, 153:598-615.

Steckelings UM, Stoppelhaar M, Sharma AM, et al. 2004. HYDRA: possible determinants of unsatisfactory hypertension control in German primary care patients. Blood Press, 13:80-8.

Swales JD. 1999. Current clinical practice in hypertension: the EISBERG (Evaluation and Interventions for Systolic Blood pressure Elevation-Regional and Global) project. Am Heart $J$, 138:231-7.

Thijs L, Den Hond E, Nawrot T, et al. 2004. Prevalence, pathophysiology and treatment of isolated systolic hypertension in the elderly. Expert Rev Cardiovasc Ther, 2:761-9.

Turnbull F; Blood Pressure Lowering Treatment Trialists' Collaboration. 2003. Effects of different blood-pressure-lowering regimens on major cardiovascular events: results of prospectively-designed overviews of randomised trials. Lancet, 362:1527-35.

Waeber B, Mourad JJ. 2006. Targeting systolic blood pressure: the key to controlling combined systolic/diastolic hypertension. Am J Hypertens, 19:985-6.

Waeber B. 2003. Trials in isolated systolic hypertension: an update. Curr Cardiol Rep, 5:427-34.

Wallace SM, Yasmin, McEniery CM, et al. 2007. Isolated systolic hypertension is characterized by increased aortic stiffness and endothelial dysfunction. Hypertension, 50:228-33.

Whitworth JA; World Health Organization, International Society of Hypertension Writing Group. 2003 World Health Organization (WHO)/International Society of Hypertension (ISH) statement on management of hypertension. J Hypertens, 2:1983-92.

Wong ND, Lopez VA, L'Italien G, et al. 2007. Inadequate control of hypertension in US adults with cardiovascular disease comorbidities in 2003-2004. Arch Intern Med, 167:2431-6.

Zieman SJ, Melenovsky V, Clattenburg L, et al. 2007. Advanced glycation endproduct crosslink breaker (alagebrium) improves endothelial function in patients with isolated systolic hypertension. $J$ Hypertens, 25:577-83. 
